\title{
Massive Extraorbital Extension in a Recurring Untreated Retinoblastoma: A Rare Case from Lebanon
}

Keywords: Orbital retinoblastoma; Recurrent retinoblastoma: Extraocular tumors; Case report; Middle east; Lebanon

\section{Abstract}

Orbital retinoblastoma usually carries a dismal prognosis. We describe a case of a 2 year old boy with a massive extraorbital recurrent unilateral retinoblastoma that was operated previously at 4 months of age. As a consequence of delayed presentation and due to poor visual prognosis and extraorbital brain metastasis, the treatment of choice was palliative exenteration. Early diagnosis and improved treatment modalities have resulted in improved eye salvage and survival. Education and public awareness about the importance of early medical diagnosis and intervention can help increase rates of early detection to improve survival rates and prevent unnecessary enucleation in underdeveloped countries.

\section{Introduction}

Retinoblastoma is the most common intraocular malignancy occurring in children, with incidence ranging from 1 in 15,000 to 1 in 18,000 live births $[1,2]$. Mortality rates are usually low if treatment is initiated before metastasis occurs [3]. Orbital retinoblastoma usually carries a poor prognosis and is associated with mortality rates as high as $50-90 \%$ in developing countries on account of delayed presentations in patients of low socioeconomic backgrounds [4-7]. Additionally, the risk of metastatic disease is reported to be higher in patients with delayed diagnosis [8]. In developing countries, metastatic retinoblastoma remains a leading cause of retinoblastoma related mortality and has been reported to range in frequency from 9-11\% [9,10]. In Lebanon, Traboulsi et al. reported data on 58 patients with retinoblastoma followed over 35 years. Data showed that although the epidemiology, genetics and clinical features of the disease were similar to those being reported worldwide, the difference was the striking delay in diagnosis resulting in higher incidences of extraocular extension, advanced disease stages and poorer survival rates [11]. We describe a case of a 2 year old boy with a massive unilateral retinoblastoma as a consequence of delayed presentation.

\section{Case Report}

This is a case of a 2 year old boy who presented for intracranial extension of a recurring retinoblastoma that was previously treated with enucleation of the right globe at the age of 4 months at another hospital with no further details available about initial presentation and treatment. A CT scan at presentation revealed an intracranial metastatic lesion without extraorbital extension (Figures 1a and 1b). In view of the poor prognosis and financial restrictions, the parents at first refused any form of medical or surgical treatment. Three months after initial presentation, the patient was brought back with

\section{Journal of}

\section{Ocular Biology}

Tania A. Baban, Fady K. Sammouh, Haytham M. EI Ballouz and Elias L. Warrak*

Department of Ophthalmology, Saint George Hospital - University Medical Center, Beirut, Lebanon

\section{*Address for Correspondence}

Elias L. Warrak, MD, FASCRS, Department of Ophthalmology, Saint George Hospital - University Medical Center, Sodeco Square, Block C, 13th floor, Beirut, Lebanon, Tel: +961 3 310828; Fax: +961 1 424220/21; E-mail: advancedeyecare.ew@gmail.com

Submission: 15 Augsut 2015

Accepted: 28 October 2015

Published: 02 November 2015

Copyright: () 2015 Baban TA, et al. This is an open access article distributed under the Creative Commons Attribution License, which permits unrestricted use, distribution, and reproduction in any medium, provided the original work is properly cited.

a massive necrotic extraorbital tumor extention of the right orbit impinging on the mouth and nostrils (Figure 2). On physical exam, the patient was febrile with a documented temperature of $38.5^{\circ} \mathrm{C}$. Blood workup was pertinent for leukocytosis with a white blood cell count of 22800/cu.mm (4000 - 11000) for which the patient received broad spectrum antibiotics. Additionally, chronic microcytic anemia was noted with a hematocrit value of $17 \%$ (40.0-54.0). Remaining blood workup, including liver function tests, electrolytes and bone scan were unremarkable. A CT scan at the time revealed massive extracranial extension involving the arteries of the circle of Willis with evidence of hydrocephalus (Figure 3). The patient was scheduled for de-bulking surgery for palliative purposes. Tumor tissue sent for pathology revealed classic histologic finding of retinoblastoma known as Flexner-Wintersteiner rosettes (Figure 4). The patient had an unremarkable postoperative course and was discharged one
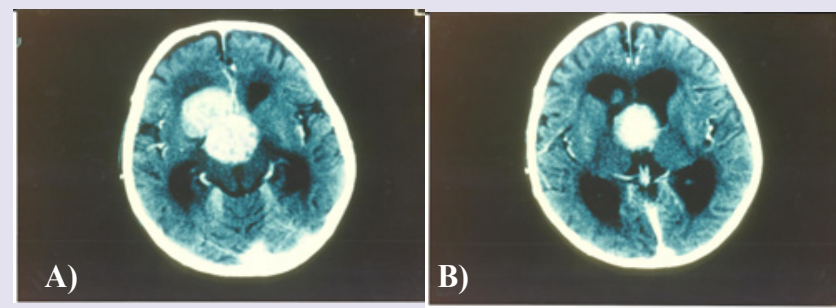

Figure 1: CT scan showing intracranial metastasis with no evidence of extraorbital extension at initial presentation.

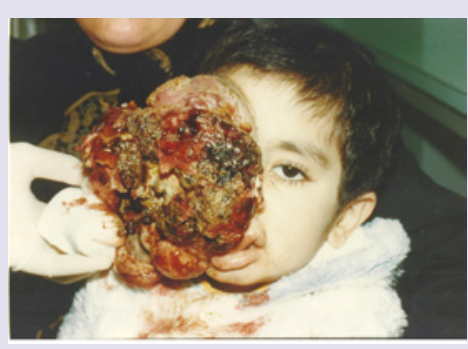

Figure 2: Massive extraorbital tumor mass impinging over the nostrils and mouth. 


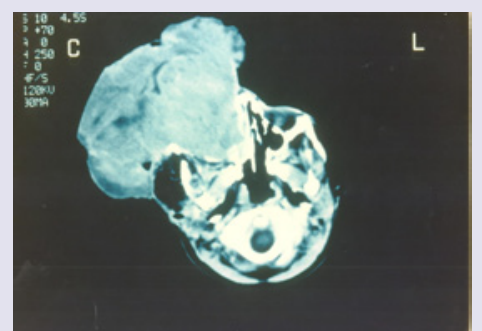

Figure 3: A CT scan showing large intracranial metastasis extending to the floor of the third ventricle with evidence of hydrocephalus.

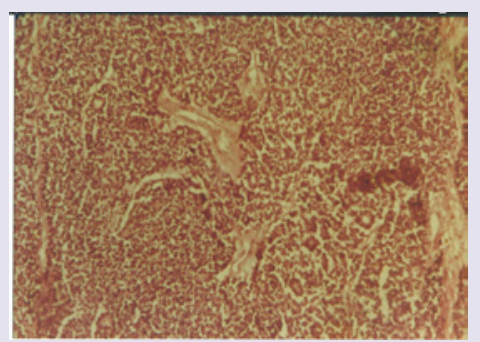

Figure 4: Microscopically, the tumor is composed of small undifferentiated cells that form rosettes. Note the presence of multiple foci of necrosis. The "Flexner-Wintersteiner" rosettes are a sign of neuroectodermal differentiation.

week later. Two weeks postoperatively, the patient was brought in for a follow up appointment with no significant findings on physical exam and was scheduled for monthly appointments. Despite multiple attempts to contact the patient's family with recurrent missed appointments, he was unfortunately lost to follow-up with no further information obtained regarding his condition and disease progression.

\section{Discussion}

The incidence of orbital retinoblastoma continues to be one of the major diagnosis at presentation in the developing world as compared to developed countries [12]. Moreover, metastatic retinoblastoma remains a major cause of retinoblastoma-related mortality in developing countries [2]. However, early diagnosis and improved treatment modalities have resulted in improved eye salvage $[12,13]$. Although advancements in medical and surgical therapies have resulted in improving survival rates worldwide, nevertheless, as seen in our case, delayed diagnosis of retinoblastoma continues to be an instrumental factor in the extensive progression of extraocular disease at presentation in developing countries [12-14]. In Lebanon, the delay in medical diagnosis could be mainly attributable to (1) the lack of medical services in rural areas (2) financial constrictions as a result of unavailable government health insurance (3) the lack of education regarding the importance of early medical interventions and (4) cultural resistance to surgical enucleation.

\section{Conclusion}

To our knowledge, this is the first reported case of a recurring retinoblastoma with massive extraorbital extension from our region. Public education and awareness of early signs and symptoms of the disease together with routine fundoscopy on all infants should be implemented in efforts to increase rates of early detection. This would improve survival rates and prevent unnecessary enucleations in underdeveloped countries.

\section{References}

1. Bishop JO, Madson EC (1975) Retinoblastoma. Review of the current status. Surv Ophthalmol 19: 342-366.

2. Gündüz K, Müftüoglu O, Günalp I, Unal E, Taçyildiz N (2006) Metastatic retinoblastoma clinical features, treatment, and prognosis. Ophthalmology 113: 1558-1566.

3. Lennox EL, Draper GJ, Sanders BM (1975) Retinoblastoma: a study of natural history and prognosis of 268 cases. Br Med J 3: 731-734.

4. Badhu B, Sah SP, Thakur SK, Dulal S, Kumar S, et al. (2005) Clinical presentation of retinoblastoma in Eastern Nepal. Clin Experiment Ophthalmol 33: $386-389$

5. Ajaiyeoba IA, Akang EE, Campbell OB, Olurin IO, Aghadiuno PU (1993) Retinoblastomas in Ibadan: treatment and prognosis. West Afr $\mathrm{J}$ Med 12: 223-227.

6. Chantada G, Fandiño A, Manzitti J, Urrutia L, Schvartzman E (1999) Late diagnosis of retinoblastoma in a developing country. Arch Dis Child 80: 171174.

7. Kodilinye HC (1967) Retinoblastoma in Nigeria: problems of treatment. Am J Ophthalmol 63: 469-481.

8. Kopelman JE, McLean IW, Rosenberg SH (1987) Multivariate analysis of risk factors for metastasis in retinoblastoma treated by enucleation. Ophthalmology 94: 371-377.

9. Günalp I, Gündüz K, Arslan Y (1996) Retinoblastoma in Turkey: diagnosis and clinical characteristics. Ophthalmic Genet 17: 21-27.

10. Leal-Leal C, Flores-Rojo M, Medina-Sansón A, Cerecedo-Díaz F, SánchezFélix S, et al. (2004) A multicentre report from the Mexican Retinoblastoma Group. Br J Ophthalmol 88: 1074-1077.

11. Traboulsi El, Jurdi-Nuwayhid F, Frangieh GT, Der Kaloustian VM (1986) Retinoblastoma in Lebanon. Ophthalmic Paediatr Genet 7: 29-34.

12. Ali MJ, Honavar SG, Reddy VA (2011) Orbital retinoblastoma: Present status and future challenges - A review. Saudi J Ophthalmol 25: 159-167.

13. Shields CL, Shields JA (2010) Retinoblastoma management: advances in enucleation, intravenous chemoreduction, and intra-arterial chemotherapy. Curr Opin Ophthalmol 21: 203-212.

14. Ali MJ, Reddy VA, Honavar SG, Naik M (2011) Orbital retinoblastoma: where do we go from here? J Cancer Res Ther 7: 11-14. 